\title{
Pilot study of sunlight exposure and vitamin D status in Arab women of childbearing age
}

A. Dawodu, ${ }^{1}$ J. Kochiyil ${ }^{2}$ and M. Altaye ${ }^{3}$

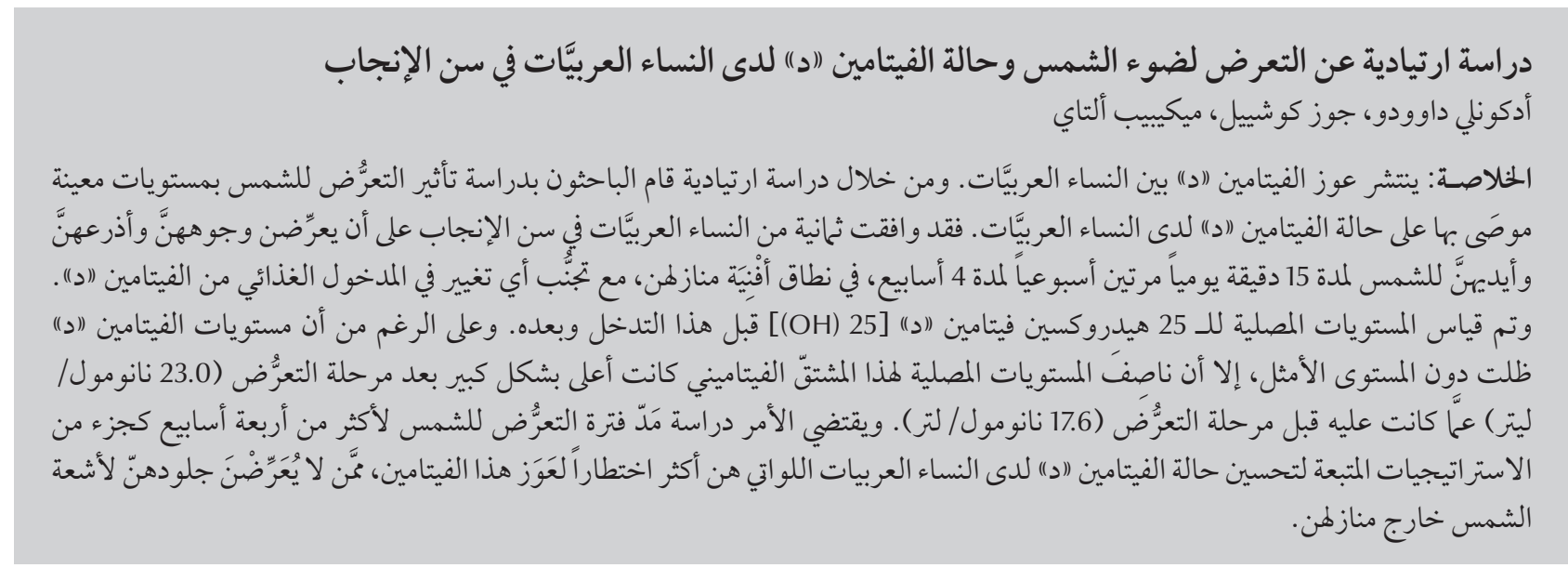

ABSTRACT Vitamin D deficiency is common in Arab women. In a pilot study we investigated the effect of sun exposure at recommended levels on the vitamin D status of Arab women. Eight healthy Arab women of childbearing age consented to expose their face, arms and hands for 15 minutes per day twice a week for 4 weeks within the privacy of their courtyard and to avoid changes in dietary vitamin D intake. Serum 25-hydroxyvitamin D $[25(\mathrm{OH})]$ levels were measured pre- and post-intervention. Although vitamin D levels remained sub-optimal, median serum 25(OH)D levels were significantly higher post-intervention $(23.0 \mathrm{nmol} / \mathrm{L})$ than pre-intervention $(17.6 \mathrm{nmol} / \mathrm{L})$. Extending sun exposure for more than 4 weeks should be investigated as part of strategies to improve vitamin D status in high-risk Arab women who lack outdoor sun exposure to the skin.

\section{Étude pilote sur l'exposition solaire et le statut en vitamine D chez des femmes arabes en âge de procréer}

RÉSUMÉ Une carence en vitamine D est fréquente chez les femmes arabes. Dans une étude pilote, nous avons analysé l'effet de l'exposition solaire aux niveaux recommandés sur le statut en vitamine D des femmes arabes. Au total, huit femmes arabes en âge de procréer et en bonne santé ont accepté d'exposer leur visage, leurs bras et leurs mains quinze minutes par jour, deux fois par semaine et pendant quatre semaines, à l'abri des regards dans leur cour, et de ne pas modifier leur apport alimentaire en vitamine D. Les valeurs sériques de la 25Hydroxyvitamine D [25(OH)] ont été mesurées avant et après l'intervention. Même si elles restaient insuffisantes, ces valeurs avaient nettement augmenté après I'intervention $(23,0 \mathrm{nmol} / \mathrm{I})$ par rapport aux résultats avant I'intervention $(17,6 \mathrm{nmol} / \mathrm{I})$. L'allongement de la durée d'exposition solaire à plus de quatre semaines devrait être étudié comme une composante des stratégies visant à améliorer le statut en vitamine D chez les femmes arabes à haut risque qui n'exposent pas suffisamment leur peau au soleil.

${ }^{7}$ Center for Global Child Health; ${ }^{3}$ Department of Epidemiology and Biostatistics, Cincinnati Children's Hospital Medical Center, Cincinnati, Ohio, United States of America (Correspondence to A. Dawodu: adekunle.dawodu@cchmc.org).

${ }^{2}$ Department of Paediatrics, Faculty of Medicine and Health Sciences, United Arab Emirates University, Al Ain, United Arab Emirates.

Received: 04/11/09; accepted: 31/12/09 


\section{Introduction}

Vitamin D is essential for bone health and calcium homeostasis [1] and has been shown to have an important role in innate immunity, autoimmune responses and cell growth and differentiation [1-3]. In addition to osteomalacia, vitamin $\mathrm{D}$ deficiency in adults has been associated with increased risk of several forms of common cancer $[1,3]$, autoimmune disorders such as type 1 diabetes [4] and susceptibility to viral and bacterial infections $[1,4]$. Furthermore, vitamin $\mathrm{D}$ deficiency and inadequate vitamin $\mathrm{D}$ intake in childhood have been associated with increased risk of lower respiratory tract infections and autoimmune diseases such as type 1 diabetes $[5,6]$.

Hypovitaminosis D has emerged as a public health problem with possible serious consequences in both adults and children $[1,7,8]$. Modest skin exposure to sunlight and dietary intake of vitamin $\mathrm{D}$ are the important determinants of vitamin D status. However, despite abundance of sunshine all year round, there is an extremely high prevalence of vitamin $\mathrm{D}$ deficiency among Arab children and women of childbearing age, probably due to avoidance of sun exposure and inadequate corrective vitamin $\mathrm{D}$ intake. Maternal vitamin $\mathrm{D}$ deficiency has been suggested to aggravate development of vitamin $\mathrm{D}$ deficiency in infants and children [7-12].

Humans derive vitamin D from endogenous synthesis and dietary sources. Depending on food fortification, the diet provides about $10 \%$ of the body's vitamin D status [13]. The major source $(90 \%)$ of vitamin D in the body is due to synthesis of vitamin $D$ from skin exposure to ultraviolet $B$ (UVB) radiation, which leads to the conversion of 7-dehydrocholesterol to pre-vitamin D3, which is then rapidly converted to vitamin D3 [13]. Prevention of low vitamin $\mathrm{D}$ status, measured by serum 25 -hydroxyvitamin $\mathrm{D}$
[25(OH)D] levels, requires modest amounts of skin sunlight exposure, food fortification with vitamin D and high dose vitamin $\mathrm{D}$ supplementation when sunlight exposure cannot be assured $[1,14,15]$. The amount of UVB available for synthesis of vitamin D depends on latitude, season, skin pigmentation, the amount of skin exposed to sunlight and the duration of sun exposure [13].

It has been suggested that outdoors direct sunlight skin exposure of the face, arms and hands for 5-10 minutes 2 or 3 times a week combined with vitamin $\mathrm{D}$ supplements is required to ensure vitamin $\mathrm{D}$ sufficiency [16]. This recommendation is based on studies undertaken among Caucasians in North America and has not been replicated in Arab women in spite of their reported high prevalence of vitamin D deficiency. Most Arab women do not take vitamin supplements, avoid sunlight and for cultural reasons wear clothing that covers the whole body except the face and hands when outdoors $[9,10,17,18]$. However, many Arab families have courtyards in their homes [A Dawodu, unpublished observation], which could provide privacy for modest skin exposure to sunlight.

The aim of this pilot study in the United Arab Emirates (UAE) was to investigate the effect of recommended levels of sun exposure within the privacy of the courtyard as part of a strategy to improve the vitamin $\mathrm{D}$ status of Arab women of childbearing age. In this study, the hypothesis tested was that a regimen of 15 minutes of exposure to sunlight of the face, arms and hands twice per week would significantly increase serum $25(\mathrm{OH}) \mathrm{D}$ concentrations. If the results were positive, it would provide initial data for an inexpensive public health measure as part of a strategy to improve vitamin D status and prevent vitamin $\mathrm{D}$ deficiency in Arab women.

\section{Methods}

\section{Setting}

The study was conducted in Al Ain, UAE at the end of the hottest months, during the period September to November 2001. The UAE is located at latitude $24^{\circ} \mathrm{N}$ and has an average of 10 hours of sunshine per day, which should favour vitamin D synthesis all the year round [13]. During the study period, the average sunshine per day ranged from 11 hours during the hot months (April to September) to 8 hours during the cool months (October to March) [11]. The study was approved by the faculty of medicine and health sciences ethics committee.

\section{Sample}

The sample was Arab women of childbearing age working in the $\mathrm{Al}$ Ain medical district, aged between 20 and 30 years, who consented to participate in the study. Twelve healthy women with high school or college education were approached; 9 agreed to participate in the study and 8 completed the study (no specific reasons for decline were given by the other 4). Women taking vitamin D supplementation, living in a home without a courtyard or who were pregnant were excluded from the study. Also excluded were individuals with a history of disorders such as chronic or severe liver disease, chronic renal disease or malabsorption, any of which are likely to affect vitamin D status [19].

\section{Data collection}

Each participant agreed to expose her face, entire arms and hands within her courtyard for 15 minutes between 10.00 and 12.00 on 2 days at the weekend. To attempt to control for changes in vitamin $\mathrm{D}$ status in response to sun exposure, participants were asked to maintain their usual dietary habits for the 4 weeks of the study.

Selected baseline biosocial data were recorded using a questionnaire, 
including age, years of education, selfreported history of amount of sun exposure per week and usual outdoor attire in the week prior to the study. The percentage of entire body surface area exposed to sunlight while outdoors was calculated using age-related body surface area charts adapted from Lund and Browder [20].

Blood samples were collected from the subjects by venepuncture during the weekday prior to and after the sun exposure interventions. The sera were separated and frozen at $-20^{\circ} \mathrm{C}$ until the time of estimation of the vitamin $\mathrm{D}$ status. Serum 25(OH)D concentrations, the most widely used assessment of body vitamin $\mathrm{D}$ status, was measured in each participant at baseline and after 4 weeks exposure of face, arms and hands to sunlight for 30 minutes per week. Serum 25(OH)D was measured by high performance liquid chromatography after extractions with acetonitrile and purification with a C-18 column, as previously described [19]. The intraand inter-assay coefficients of variation were $4 \%$ and $5.3 \%$, respectively. Serum $25(\mathrm{OH}) \mathrm{D}<50 \mathrm{nmol} / \mathrm{L}(20 \mathrm{ng} / \mathrm{mL})$ was considered as vitamin $\mathrm{D}$ deficiency [1] and $<25 \mathrm{nmol} / \mathrm{L}$ was considered as moderate vitamin $\mathrm{D}$ deficiency [21].

\begin{tabular}{|c|c|c|}
\hline Characteristic & Median & Range \\
\hline Age (years) & 24 & $23-28$ \\
\hline Years of education & 17 & $16-19$ \\
\hline $\begin{array}{l}\text { Reported usual intentional outdoor sun } \\
\text { exposure (min/week) }\end{array}$ & 0 & $0-30$ \\
\hline \% body surface area usually exposed to sunlight & 9 & $4-9$ \\
\hline $\begin{array}{l}\text { Serum } 25 \text {-hydroxyvitamin D concentration } \\
(\mathrm{nmol} / \mathrm{L})\end{array}$ & 17.6 & $3.8-23.8$ \\
\hline
\end{tabular}

\section{Data analysis}

Comparisons were made of the changes between subjects in the duration of sun exposure in minutes and the percentage of body surface area exposed to sunlight before and during the intervention and the pre- and post-intervention serum $25(\mathrm{OH}) \mathrm{D}$ concentrations. A nonparametric Wilcoxon sign rank test was used to analyse the data because of the small sample size and lack of normal distribution. $P$-values $<0.05$ were considered significant.

\section{Results}

The baseline characteristics of the 8 women who completed the study protocol are summarized in Table 1. The median (range) minutes of sun exposure per week was 0 minutes (0-30) preintervention and 30 minutes (0-30) during the intervention. The median (range) body surface area exposed to sunlight was calculated as 9\% (4\%-9\%) pre-intervention and 23\% (17\%-23\%) during the intervention.

The median serum 25(OH)D concentration was significantly higher post-intervention $[23.0 \mathrm{nmol} / \mathrm{L}$ (range 13.0-37.5)] compared with baseline levels $[17.6 \mathrm{nmol} / \mathrm{L}$ (range 3.8-23.8)] $(P=0.02)$. Thus the median serum 25( OH)D level increased by $5.4 \mathrm{nmol} / \mathrm{L}$, a $31 \%$ increase after 4 weeks of increased sun exposure. Individual changes in serum $25(\mathrm{OH})$ $\mathrm{D}$ concentration in the 8 women who completed the study protocol are shown on Figure 1.

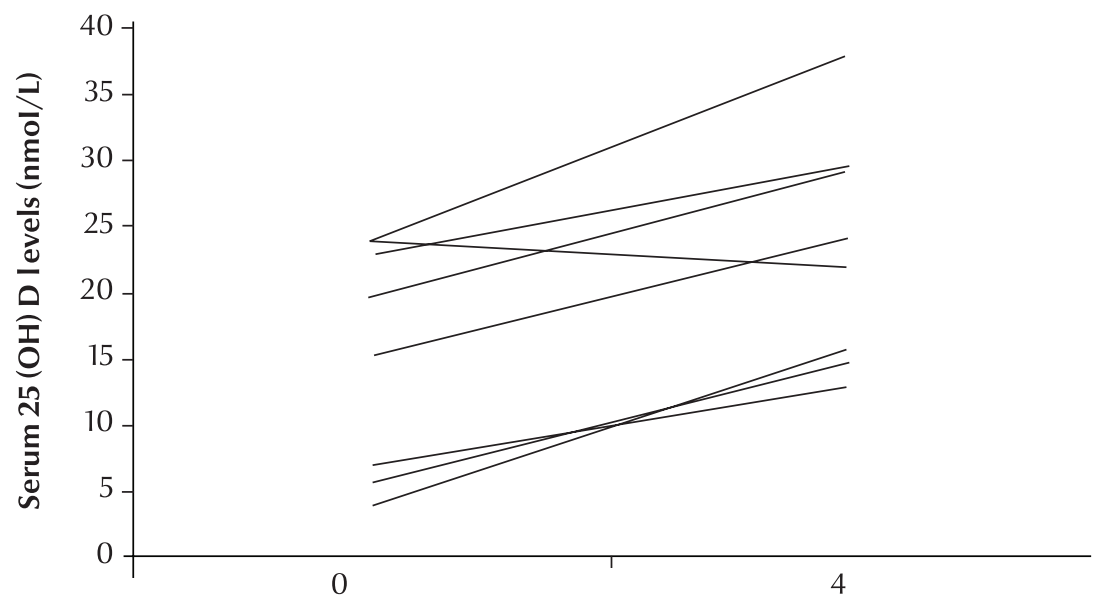

Time (weeks)

Figure 1 Individual changes in the 8 women's serum 25-hydroxyvitamin D [25(OH)D] concentrations after 4 weeks of exposure to sunlight for 30 minutes per week $(n=8)$ 
Despite a significant post-intervention increase in serum $25(\mathrm{OH}) \mathrm{D}$ concentrations, all the women still had subclinical vitamin D deficiency [serum $25(\mathrm{OH})$ D levels $<50 \mathrm{nmol} / \mathrm{L}$ ] because of their very low baseline vitamin $\mathrm{D}$ status. The sub-clinical vitamin $\mathrm{D}$ deficiency was moderate [serum $25(\mathrm{OH}) \mathrm{D}<$ $25 \mathrm{nmol} / \mathrm{L}]$ in all the women at baseline and in 5 women post-intervention.

\section{Discussion}

The major limitation of this pilot study was the small size sample and the lack of a non-intervention control group. However, the objective was to compare the impact ofincreased skin sun exposure on serum 25(OH)D concentration in each participant. Our investigation confirms the low vitamin $\mathrm{D}$ status among Arab women in the study. A high prevalence of moderate vitamin $\mathrm{D}$ deficiency in the subjects enrolled in the study is similar to findings in other studies from the community and the region $[7-9,12,17]$ and suggests a need for urgent action to prevent vitamin D deficiency in Arab women. The study also shows that a modest improvement in vitamin $\mathrm{D}$ status as measured by serum $25(\mathrm{OH}) \mathrm{D}$ concentrations could be achieved from 30 minutes of modest sunlight exposure per week of the face, arms and hands among high-risk women of childbearing age in Arab communities.

There are no reported studies of the effect of modest direct sunlight exposure on the vitamin D status of women of child-bearing age for comparison. However, the mean increase in serum 25(OH)D concentrations of 5.4 $\mathrm{nmol} / \mathrm{L}$ is similar to changes in serum $25(\mathrm{OH}) \mathrm{D}$ concentrations after exposure to sunlight reported in elderly patients in other countries $[17,22]$. Elderly Caucasians with a mean age of 80 years from an Auckland residential home had a mean increase of $7.0 \mathrm{nmol} / \mathrm{L}$ in serum $25(\mathrm{OH}) \mathrm{D}$ concentration after 4 weeks of exposing their head, neck, forearms and lower legs to sunlight for 15 minutes per day [22]. Compared with the results of this study, the finding in the elderly shows a smaller increase considering that the body surface area exposed to sunlight was greater and the duration of exposure was 100 minutes per week compared with 30 minutes per week in this study. This may be related to the effect of age, since the endogenous synthesis of vitamin $\mathrm{D}$ is lower in the elderly compared with young adults [13].

Two-thirds of the 12 women approached completed the study according to the protocol. Therefore, the exposure of the face, arms and hands to sunlight within the privacy of a courtyard seems to be acceptable to the Arab women in this pilot study and this could be tested in larger studies. It would have been helpful to monitor changes in pigmentation before and after intervention to assess the effect of the sun exposure. Studies that investigated the decline of increased serum 25(OH)D levels in subjects exposed to modest artificial ultraviolet (UV) radiation, found that elevated serum $25(\mathrm{OH}) \mathrm{D}$ concentrations returned to initial baseline values 8 weeks after termination of commercial UV exposure [23]. Therefore, regular modest skin exposure to direct sunlight, if acceptable and sustained, could theoretically be effective in improving vitamin $\mathrm{D}$ status and reducing the prevalence of vitamin D deficiency. Further research is required to test such a hypothesis.

The major factors that could have contributed to the increase in serum 25( OH)D concentration include the increased surface area of the skin exposed and the duration of exposure to sunlight, dietary intake of vitamin $\mathrm{D}$ and season $[1,13]$. Although the numbers were small, the pre-intervention sun exposure behaviour in this study group is similar to the findings in other larger studiesfrom thiscommunity $[11,12,18]$. In previous studies, women of childbearing age were reported to wear clothing that covers the whole body except for the face and hands $[18,24]$ and the mean sunlight exposure per week was only 4.9 minutes [18]. The dietary intake of vitamin $\mathrm{D}$ among the women in this study was not assessed. However, previous studies indicate that the daily dietary vitamin $\mathrm{D}$ intake among women in this population and other Middle Eastern countries $[9,12,17,19]$ is below the recommended intake of $400 \mathrm{IU}$ of vitamin D per day. Furthermore, the subjects studied agreed not to change their dietary habits during the study period and were not taking vitamin $\mathrm{D}$ supplementation. Therefore, changes in dietary vitamin $\mathrm{D}$ intake are unlikely to explain the increase in serum $25(\mathrm{OH})$ $\mathrm{D}$ concentrations post-intervention.

We believe that the changes in serum $25(\mathrm{OH}) \mathrm{D}$ concentrations observed are related to the higher skin surface area exposed to sunlight and the modest increase in the duration of sunshine exposure during the intervention. The increase in serum $25(\mathrm{OH})$ $\mathrm{D}$ concentration was unlikely to have been affected by the season of the study as there is abundant sunshine throughout the year in the UAE which favours vitamin $D$ synthesis $[1,13]$. This suggestion is supported by a study from this environment which shows a lack of significant seasonal changes in vitamin $\mathrm{D}$ levels [12]. Among those Arab women whose lifestyle limits outdoor skin sun exposure, maximizing the body surface area and the time exposed to sunlight within the privacy of a courtyard should be explored as a method to improve vitamin $\mathrm{D}$ status. This hypothesis needs to be tested in a larger and longer study.

Although some authors have suggested vitamin D supplementation as the main strategy to improve vitamin D status [25], others have advocated a need to promote safe and culturally acceptable skin sun exposure $[13,15]$ as part of the strategy to improve vitamin D status. After review of the literature, this is the first study to investigate the impact of currently recommended modest direct skin exposure to sunlight 
on the vitamin D status of Arab women with a high prevalence of vitamin $D$ deficiency and is of public health importance. Given the biological response of serum 25(OH)D concentrations during a relatively short period, extending the sunlight exposure for more than 4 weeks with a larger sample size should be investigated as an inexpensive measure as part of strategies to improve the vitamin D status in high-risk women in Arab communities and reduce the risk of vitamin $\mathrm{D}$ deficiency in infants. Future studies might include a control group of women taking oral vitamin supplements.

\section{References}

1. Holick MF. Vitamin D deficiency. New England Journal of Medicine, 2007, 357:266-281.

2. Liu PT et al. Toll-like receptor triggering of a vitamin D-mediated human antimicrobial response. Science, 2006, 311:17701773.

3. Gorham ED et al. Vitamin D and prevention of colorectal cancer. Journal of Steroid Biochemistry and Molecular Biology, 2005, 97:179-194.

4. Chiu KC et al. Hypovitaminosis D is associated with insulin resistance and beta cell dysfunction. American Journal of Clinical Nutrition, 2004, 79:820-825.

5. Hyppönen E et al. Intake of vitamin D and risk of type 1 diabetes: a birth-cohort study. Lancet, 2001, 358:1500-1503.

6. Wayse $\mathrm{V}$ et al. Association of subclinical vitamin $\mathrm{D}$ deficiency with severe acute lower respiratory infection in Indian children under 5 y. European Journal of Clinical Nutrition, 2004, 58:563-567.

7. Dawodu A, Wagner CL. Mother-child vitamin D deficiency: an international perspective. Archives of Disease in Childhood, 2007, 92:737-740.

8. Mithal A et al. Global vitamin D status and determinants of hypovitaminosis D. Osteoporosis International, 2009, 20:18071820.

9. Gannagé-Yared MH et al. Hypovitaminosis D in a sunny country: relation to lifestyle and bone markers. Journal of Bone and Mineral Research, 2000, 15:1856-1862.

10. Dawodu A et al. Diet, clothing, sunshine exposure and micronutrient status of Arab infants and young children. Annals of Tropical Paediatrics, 2001, 21:39-44.

11. Dawodu A et al. Contribution of sunshine deprivation and maternal vitamin D deficiency to rickets in the United Arab Emirates. Emirates Medical Journal, 2006, 24:29-35.

12. Saadi HF et al. Predictors and relationships of serum 25 hydroxyvitamin D concentration with bone turnover markers, bone mineral density, and vitamin $\mathrm{D}$ receptor genotype in Emirati women. Bone, 2006, 39:1136-1143.

13. Holick MF. Sunlight and vitamin D for bone health and prevention of autoimmune diseases, cancers, and cardiovascular disease. American Journal of Clinical Nutrition, 2004, 80(Suppl.):1678S-1688S.
14. Hollis BW. Circulating 25-hydroxyvitamin D levels indicative of vitamin D sufficiency: implications for establishing a new effective dietary intake recommendation for vitamin D. Journal of Nutrition, 2005, 135:317-322.

15. Vieth $\mathrm{R}$ et al. The urgent need to recommend an intake of vitamin D that is effective. American Journal of Clinical Nutrition, 2007, 85:649-650.

16. Holick MF. Photosynthesis, metabolism, and biologic actions of vitamin D. In: Glorieux FH, ed. Rickets. Nestle Nutritional Workshop Series volume 21. New York, Raven Press, 1991:1-22.

17. Sedrani SH, Elidrissy AW, El Arabi KM. Sunlight and vitamin D status in normal Saudi subjects. American Journal of Clinical Nutrition, 1983, 38:129-132.

18. Saadi HF et al. Efficacy of daily and monthly high-dose calciferol in vitamin D-deficient nulliparous and lactating women. American Journal of Clinical Nutrition, 2007, 85:1565-1571.

19. Dawodu A et al. Hypovitaminosis D and vitamin D deficiency in exclusively breast-feeding infants and their mothers in summer: a justification for vitamin D supplementation of breastfeeding infants. Journal of Pediatrics, 2003, 142:169-173.

20. Lund C, Browder N. The estimation of areas of burns. Surgery, Gynecology \& Obstetrics, 1944, 79:352-358.

21. Lips P. Vitamin D deficiency and secondary hyperparathyroidism in the elderly: consequences for bone loss and fractures and therapeutic implications. Endocrine Reviews, 2001, 22:477-501.

22. Reid IR, Gallagher DJ, Bosworth J. Prophylaxis against vitamin $\mathrm{D}$ deficiency in the elderly by regular sunlight exposure. Age and Ageing, 1986, 15:35-40.

23. Porojnicu $A C$ et al. Sun beds and cod liver oil as vitamin D sources. Journal of Photochemistry and Photobiology. B, Biology, 2008, 91:125-131.

24. Dawodu A et al. Biosocial factors affecting vitamin D status of women of childbearing age in the United Arab Emirates. Journal of Biosocial Science, 1998, 30:431-437.

25. Wolpowitz D, Gilchrest BA. The vitamin D questions: how much do you need and how should you get it? Journal of the American Academy of Dermatology, 2006, 54:301-317. 